\title{
WHO USES TINDER?: THE DARK TRIAD TRAITS, ATTACHMENT, AND MATE VALUE
}

PETER JONASON *

Western Sydney University, Australia

RACHEL BULYK

Western Sydney University, Australia

\begin{abstract}
Modern dating life has been changed with the advent of smartphone-based applications like Tinder. One way to identify who uses these applications is to compare the personality traits of users to non-users. In two brief studies $(N=581)$ we compared Tinder-users to non-users in individual differences associated with short-term mating (i.e., psychopathy, Machiavellianism, narcissism [the Dark Triad traits], and anxious attachment) and mate value. We revealed that the men who were Tinder users were especially high in psychopathy and narcissism and women who were Tinder users were especially high in anxious attachment and rated themselves as unsuccessful in finding relationship partners. While exploratory in nature, we suggest that men who are characterized by antisocial traits may use Tinder for opportunistic mating goals whereas women who have struggled to find relationships may use Tinder as a compensatory mating tactic.
\end{abstract} MACHIAVELLIANISM ATTACHMENT MATE VALUE DIFFERENCES

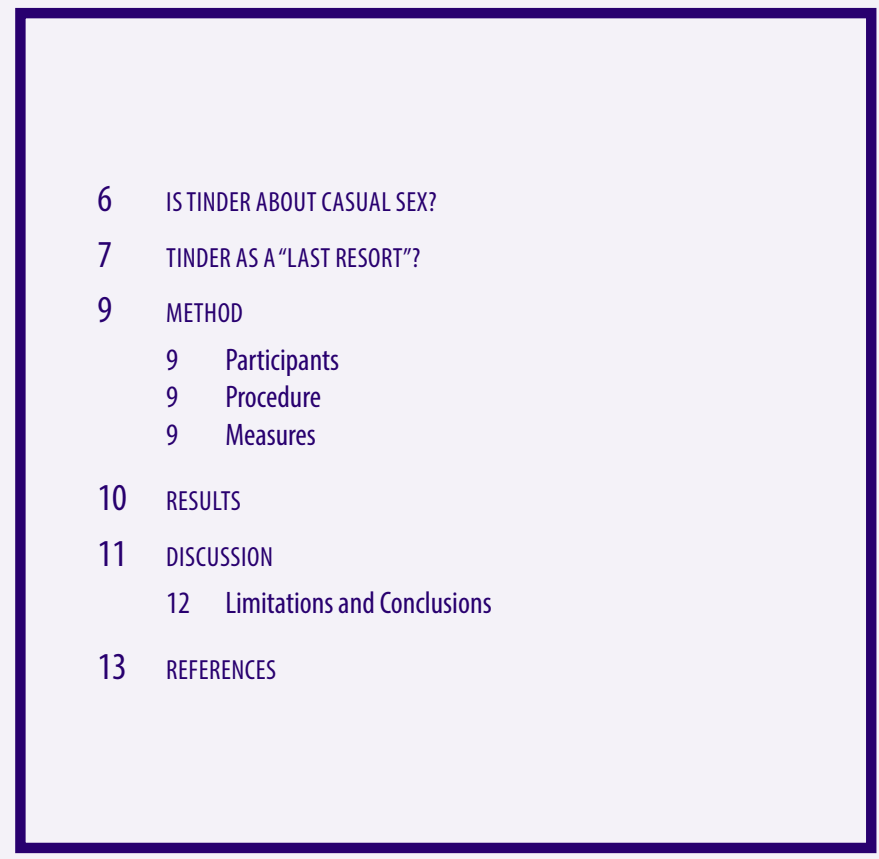


bout a decade ago, the dating world was changed drastically with the advent of Tinder (Duggan \& Smith, 2014; Duguay, 2016; Sales, 2015). Tinder is an application that people use on their smartphones to enable them to meet new people for potential relationships. It relies on the Global Positioning System in people's smartphones, allowing them to connect with others within a pre-determined distance from them. People create picture-heavy profiles to entice potential suitors to "swipe right" (i.e., to choose) for them. This approach to dating is distinct from "traditional" forms where people go to physical places like nightclubs, churches, and libraries (Jonason, Foster, McCain, \& Campbell, 2015) to find partners and allows people to relatively passively search for new partners who are near them for sex or love. Given the novelty of this approach to relationships, there has been considerable research on who uses and why they use Tinder (e.g., Clemens, Atkins, \& Krishnan, 2015; Timmermans \& De Caluwé, 2017a, 2017b) and even how people abuse and bully one another in these online dating spaces (e.g., March, Grieve, Marrington, \& Jonason, 2017). We capitalize on this research trend and attempt to provide new information about who uses Tinder, replicating and qualifying some effects and extending it by including other variables yet to be examined.

\section{IS TINDER ABOUT CASUAL SEX?}

Research and stereotypes agree about Tinder; it is often used for casual sex (see Gatter \& Hodkinson, 2016; Sevi, 2019). For example, Tinder use is associated with promiscuous sexual attitudes (i.e., sociosexuality), risk-taking, and limited sexual disgust (Botnen, Bendixen, Grøntvedt, \& Kennair, 2018; Sevi, 2018; Sevi, Aral, \& Eskenazi, 2018). This suggests those who are more likely to be interested in casual sex are ones most likely to be present on Tinder. In addition, the reasons people self-report for using Tinder focus on casual sex motives including seeking new partners (Carpenter \& McEwan, 2016; Daneback, Månsson, \& Ross, 2007; Sumter, Vandenbosch, \& Ligtenberg, 2017). Assuming people use Tinder for casual sex, we would expect those who are biased towards liking and pursuing casual sex to use Tinder.

The Dark Triad traits of narcissism (e.g., vanity and self-centeredness), Machiavellianism (e.g., manipulation and cynicism), and psychopathy (e.g., callous social attitudes and amorality) along with anxious attachment (e.g., relationship insecurity) are linked to casual sex attitudes and behaviors (Brennan \& Shaver, 1995; Jonason, Li, Webster, \& Schmitt, 2009; Schmitt \& Jonason, 2015; Sprecher, 2013). Those characterized by the Dark Triad traits (for review see Koehn, Okan, \& Jonason, 2019) have a willingness to lower their standards in their sex partners (Jonason, Valentine, Li, \& Harbeson, 2011) and have promiscuous sociosexual attitudes (Jonason et al., 2009), suggesting they may be present on Tinder if joining up is at least partially motivated by casual sex. Indeed, those who use Tinder appear to be higher in the Dark Triad traits and have casual sex motives (Sevi, 2019; Timmermans, De Caluwé, \& Alexopoulos, 2018). However, there is an additional reason to expect those who use Tinder to be high on the Dark Triad traits. These traits are linked to various manifestations of aggression including online coercive sexual behavior (Duncan \& March, 2019) and cyberbullying (March et al., 2017). The nature of the application (like most dating applications) unintentionally promotes the active exploitation and abuse of 
others with features like limited feedback from others during and after interactions and the veil of anonymity may make this online niche particular appealing to those set on taking advantage and abusing others. Given that the Dark Triad traits may enable people to be simultaneously aggressive and sexual towards others-both fundamental aspects of their personality - we expect those who use Tinder to be higher on the Dark Triad traits than those who do not (H1).

Beyond replicating the differences related to the Dark Triad traits, we extend this to include attachment and mate value. In contrast, to the Dark Triad traits, those who have an insecure or anxious attachment pattern may engage in casual sex for different reasons, potentially doing so out of a need to connect with others. Attachment is a set of relationship expectancies derived from childhood experiences (Ainsworth, Blehar, Waters, \& Wall, 1978; Hazan \& Shaver, 1987; Shaver \& Brennan, 1992) which may play a role in decision-making in relationships (Batholomew \& Horowitz, 1991; Milkulincer \& Shaver, 2003) and may account for why people engage in casual sex (Brennan \& Shaver, 1995; Schmitt \& Jonason, 2015; Sprecher, 2013). Anxiously attached people have a need to be loved as a substitute for an erratic relationship with a caregiver and, therefore, may engage in casual sex whereas avoidant people have developed an ambivalence to relationships because of a lack of positive interactions with caregivers (Batholomew \& Horowitz, 1991; Schachner \& Shaver, 2004). Indeed, anxiously attached Rhesus monkeys (Macaca mulatta) try to have sex but are often inept whereas avoidantly attached monkeys simply withdraw from sexual and social life (for review see Cassidy \& Shaver, 1999). If those who use Tinder are looking for casual sex, they may be more anxiously attached than those who do not use Tinder (H2).

In addition, we also expect these effects to depend on the sex of the Tinder user. For instance, men are better characterized by the Dark Triad traits around the world (Jonason et al., 2017) and are more interested in casual sex (Buss \& Schmitt, 1993) than women are. As part of their short-term mating agenda, men high on the Dark Triad traits may be especially likely to be on Tinder if Tinder is used for casual sex encounters; there is less evidence that men are more aggressive than women are online (March et al., 2017) making the aggression motive less likely. That is, because the traits facilitate short-term mating in men more than women (Jonason et al., 2009; Jonason et al., 2011), male Tinder users should be better characterized by the Dark Triad traits than non-users (H1a). In contrast, because boys might respond to insecure attachment differently than girls do, female Tinder users might be more anxiously attached than non-users (H2a). Problematic childhood conditions (e.g., father absence) may encourage boys to become antisocial (e.g., psychopathy; Jonason, Lyons, \& Bethell, 2014) whereas similar conditions for girls may lead to an increased drive to connect as seen in promiscuous behavior (Kruger \& Fisher, 2008). That is, because of the higher value women place on social connection and family relations compared to men (Jonason \& Zeigler-Hill, 2018), women with anxious attachment patterns may seek out casual sex to feel that sense of connection they were missing as a child and may continue to be missing as adults.

\section{TINDER AS A “LAST RESORT”?}

Despite the popularity of Tinder (and other dating applications), we suspect that people would rather meet the "old fashioned" way like in bars or at school (Jonason, Foster et al., 2015). The adoption of dating applications like Tinder have introduced a variety of new problems like "bread-crumbing" (i.e., having little bits of conversations to keep a potential partner on the hook without engaging too much), "ghosting" (i.e., vanishing in the middle of a conversation with no explanation), "cat-fishing" (i.e., falsely representing oneself), and 
"dog-fishing" (i.e., faking dog ownership) which are much less problematic, even absent, when two people have met in-person from day one. And yet, knowing these new risks, some people choose to use Tinder. One reason people might do so is that they feel they have few other choices; it is a compensatory mating tactic. People may have struggled and failed so often in live exchanges that they may choose Tinder as a "last resort" to find partners.

Evolutionary psychologists suggest one reason people struggle to find relationship partners is their mate value. Mate value, broadly defined, is related to the qualities a person possesses that are valued by others who might consider dating or having sex with them (Fisher, Cox, Bennett, \& Gavric, 2008; Regan, 1998). Those with more mate value are better able to optimize their mating goals because they are more desirable than others; more mate value acts as more bargaining power in sexual economic terms. Those who think they have more value will behave differently in relationship contexts as well. For instance, those with more self-perceived mate value have more relationship dealbreakers (Jonason, Garcia, Webster, Li, \& Fisher, 2015) and are more particular with whom they wish to date (Edlund \& Sagarin, 2010). Examining related traits like shyness, low self-esteem, desperation, and anxiety (Aretz, Demuth, Schmidt, \& Vierlein, 2010; Duggan \& Smith, 2014; Kim, Kwon, \& Lee, 2009; Kraut et al., 2002; Kraut et al., 1998; Valkenburg \& Peter, 2007; Whitty \& Buchanan, 2009) have revealed conflicting results, perhaps because mate value is the more salient individual difference. If this is true, those who have used Tinder may report a general lack of success or desirability on the mating market (H3) and if Tinder use is about shortterm mating, those who have used Tinder should report lower rates of short-term (e.g., physical attractiveness), but not necessarily long-term (e.g., good parenting ability) mate value $(\mathrm{H} 3 \mathrm{a})$.

Last, we expect that it will be women, more than men, who use Tinder as a compensatory mating tactic. Men tend be sexually opportunistic (Jonason et al., 2011). Given that women tend to control access to sex (Buss \& Schmitt, 1993), men may engage in bet-hedging in their mating efforts regardless of their mate value whereas women, who may be better able to optimize their sexual agenda than men are, can adopt compensatory mating tactics in response to feedback they get from the world (Jonason, Garcia et al., 2015; Regan, 1998). For example, it is women, not men, with a sense of high mate value, who are especially likely to reject partners who are not intelligent enough in their view (Jonason et al., 2019). Men who use Tinder may do so not because of a sense of diminished mate value as much as willingness to try various strategies to optimize their mating success. In contrast, those women who feel they high mate value may think they can find someone in real life, and, therefore, are unlikely to engage in Tinder use. In contrast, it is women who think they have low value who may feel compelled to adopt Tinder in hopes of finding a partner based on their experience with failures in their romantic goals. Therefore, we expect female (not male) Tinder users to be lower in self-reported mating success than those who have not used Tinder (H3b).

We test two main assertions. We test the idea that (1) those who use Tinder are characterized by antisocial personality traits (Sevi, 2019) and have an anxious attachment pattern and that (2) using Tinder is a mating strategy of "last resort" that is engaged in by those who are relatively undesirable as a relationship partner. We examine these effects overall and in men and women. 


\section{METHOD}

\section{PARTICIPANTS}

We collected two Mechanical Turk samples of American participants who were paid (US\$0.50) to participate in two, larger independent studies on personality and relationship psychology (Jonason, Betes, \& Li, in press). The minimum sample size in both studies was determined based on the average effect size in social and personality psychology $(r \approx .20$; Richard, Bond, \& Stokes-Zoota, 2003$)$ and guidelines $(N \approx 250)$ set for reducing estimation error in personality psychology (Schönbrodt \& Perugini, 2013). In Study 1, there were 299 participants ( $45 \%$ female, $55 \%$ male) aged $18-61(M=32.56, S D=9.44)$, who were mostly in some form of serious relationship (56\%), were heterosexual (94\%), and white/European (72\%). ${ }^{1,2}$ In Study 2 (collected one month later than Study 1), there were 282 (59\% female, $40 \%$ male $)$ aged $18-72(M=34.75, S D=10.85)$ who were mostly in some form of serious relationship (74\%), heterosexual (94\%), and white/European (74\%). ${ }^{3,4}$

\section{PROCEDURE}

The participants were informed of the nature of the study. If they gave consent, they advanced through a series of randomized self-report measures and provided demographic details. Upon completion, they were thanked and debriefed. These studies were approved by the ethics committee at Western Sydney University (H14099).

\section{MEASURES}

In both studies, we measured Tinder use with a single-item. Participants were asked, whether (yes/no) they had used the dating application Tinder (or similar) in the last year. By asking about use over the last year, we minimized the influence of whether people are in a relationship now and focused on a behavioroid measure of Tinder use. We focused on Tinder in our question given its popularity (Duguay, 2016). Analyses will, therefore, compare (i.e., $t$-tests) users to non-users on the following individual differences similar to previous work (Sevi, 2019; Timmermans et al., 2018). ${ }^{5}$

In Study 1, we measured the Dark Triad traits with the 27-item Short Dark Triad scale (Jones \& Paulhus, 2014). Participants were asked to report their agreement (1 = Strongly disagree; 5 = Strongly agree) with statements measuring Machiavellianism (e.g., "Most people are suckers."), narcissism (e.g., "I am an average person."), and psychopathy (e.g., "I like to pick on losers."). Items were averaged to create indexes of Machiavellianism (Cronbach's $\alpha=.81)$, narcissism $(\alpha=.80)$, and psychopathy $(\alpha=.80){ }^{6}$

\footnotetext{
Asian (12\%), Hispanic/Latino (9\%), African/Black (5\%), and “other” (2\%).

2 Older people (by about 3 years) were more likely to use Tinder than younger ones $(t=2.16$; $p<.05)$.

3 Asian (9\%), Hispanic/Latino (8\%), African/Black (7\%), and “other” (2\%).

4 Younger people (by about 4 years) were more likely to use Tinder than older ones $(t=-2.41 ; p<.05)$.

5 Results are the same when using biserial correlations.

6 Narcissism was correlated with psychopathy $(r[297]=.51 ; p<.01)$ and Machiavellianism $(r[297]=.41$; $p<.01)$ and psychopathy was correlated with Machiavellianism $(r[60]=.60 ; p<.01)$.
} 
In Study 2, we measured self-reported mate value with Li's Mate Value scale (Li, 2017; see Jonason et al., 2019). Participants were asked their agreement $(1=$ Strongly disagree; 7 = Strongly agree) with 20 items presented in a randomized fashion. Items were averaged to create indexes of attractiveness as a short-term mate (e.g., "Compared to my peers, I am very attractive or desirable to the opposite sex."; $\alpha=.87$ ), attractiveness as a long-term mate (e.g., "People seem to be interested in having a long-term relationship with me."; $\alpha=.77$ ), and a general unattractiveness or difficulty in relationships factor (e.g., "I tend to have a more difficult time attracting potential mates than other people do."; $\alpha=.90){ }^{7}$

\section{RESULTS}

In Study 1 , most $\left(\chi^{2}=16.04 ; p<.01\right)$ of the participants had not used Tinder $(n=227,76 \%)$ in the last year compared to those who had $(n=77,34 \%)$; with no sex difference in use $\left(\chi^{2}=\right.$ 0.34). In Study 2, most of the participants had not used Tinder $(n=217,77 \%)$, with fewer $\left(\chi^{2}=17.60, p<.01\right)$ having used it $(n=65,33 \%)$. In Study 2 , there were far fewer women $(n=27)$ who used Tinder $\left(\chi^{2}=11.05, p<.01 ; \Phi=-.20\right)$ as compared to those who did not $(n=139)$, with a smaller difference between men who used them and men who did not. Nevertheless, given the imbalance in cell sizes of users-to-nonusers overall and in each sex, we maximized sensitivity with planned comparisons (i.e., $t$-tests as opposed to ANOVAs); comparing those who used Tinder to those who did not. We report descriptive statistics in Table 1. Given the imbalance of sample sizes, we urge the reader to (1) use caution in interpreting the null hypothesis tests and (2) focus on effect sizes.

Table 1. Descriptive statistics (M [SD]) comparing Tinder users to non-users on the Dark Triad traits (Study 1), attachment, and self-reported mate value (Study 2)

\begin{tabular}{|c|c|c|c|c|c|c|}
\hline & \multicolumn{3}{|c|}{ Not used dating apps } & \multicolumn{3}{|c|}{ Used dating apps } \\
\hline & \multicolumn{6}{|c|}{ Study 1} \\
\hline & Overall & Men & Women & Overall & Men & Women \\
\hline & $n=231$ & $n=126$ & $n=105$ & $n=68$ & $n=39$ & $n=29$ \\
\hline Machiavellianism & $2.87(0.81)$ & $2.97(0.73)$ & $2.76(0.88)$ & $3.06(0.70)$ & $3.21(0.74)$ & $2.86(0.61)$ \\
\hline Narcissism & $2.65(0.77)$ & $2.73(0.75)$ & $2.55(0.79)$ & $2.87(0.65)$ & $3.00(0.62)$ & $2.71(0.66)$ \\
\hline \multirow[t]{3}{*}{ Psychopathy } & $2.05(0.71)$ & $2.28(0.71)$ & $1.78(0.61)$ & $2.40(0.89)$ & $2.74(0.91)$ & $1.95(0.64)$ \\
\hline & \multicolumn{6}{|c|}{ Study 2} \\
\hline & $n=216$ & $n=76$ & $n=139$ & $n=66$ & $n=38$ & $n=27$ \\
\hline STM Value & $4.74(1.49)$ & $4.83(1.41)$ & $4.70(1.54)$ & $5.11(1.45)$ & $5.05(1.42)$ & $5.25(1.50)$ \\
\hline LTM Value & $6.16(0.92)$ & $6.12(0.84)$ & $6.19(0.96)$ & $6.05(1.04)$ & $6.00(1.00)$ & $6.06(1.08)$ \\
\hline General Undesirability & $3.23(1.67)$ & $3.60(1.78)$ & $3.03(1.58)$ & $4.57(1.75)$ & $4.24(1.80)$ & $5.03(1.61)$ \\
\hline Anxious Attachment & $3.64(1.51)$ & $3.81(1.54)$ & $3.54(1.50)$ & $4.38(1.55)$ & $4.03(1.55)$ & $4.96(1.36)$ \\
\hline Avoidant Attachment & $3.32(1.23)$ & $3.30(1.30)$ & $3.34(1.20)$ & $3.52(1.23)$ & $3.38(1.18)$ & $3.69(0.99)$ \\
\hline
\end{tabular}

Note. STM = short-term mate; LTM = long-term mate.

In accordance with $\mathrm{H} 1$ (i.e., Tinder use $\approx$ short-term mating/aggression space), those who used Tinder in the last year (compared to those who did not) were more narcissistic

\footnotetext{
Short-term and long-term mating attractiveness were correlated $(r[280]=.37, p<.01)$. Long-term mating attractiveness was correlated with general undesirability $(r[280]=.39, p<.01)$ and anxious attachment $(r[280]=$ $.31, p<.01)$. And general undesirability was correlated with anxious attachment $(r[280]=.77, p<.01)$.
} 
$(t[297]=-2.19 ; p<.05$, Cohen's $d=-0.25)$, anxiously attached $(t[280]=3.45, p<.01 ; d=$ $0.41)$, psychopathic $(t[297]=-3.34, p<.01, d=-0.39)$, and (slightly) more Machiavellianism $(t[297]=-1.74, p<.09, d=-0.20) .{ }^{8} \mathrm{H} 1 \mathrm{a}$ and $\mathrm{H} 2 \mathrm{a}$ suggests these effects should be stronger in men for the Dark Triad traits and stronger in women for anxious attachment. Consistent with that, effects were localized to men for (slightly) Machiavellianism $(t[163]$ $=-1.78, p<.08, d=-0.28)$, narcissism $(t[163]=-2.04, p<.05, d=-0.32)$, and psychopathy $(t[163]=-3.26, p<.01 ; d=-0.51)$ and localized to women for anxious attachment $(t[164]$ $=4.56, p<.01, d=0.71$ ).

In accordance with $\mathrm{H} 3$ and $\mathrm{H} 3 \mathrm{a}$ (i.e., lack of mating success and low short-term mate value should be associated with Tinder use), we found that those who saw themselves as generally undesirable $(t[280]=5.65, p<.01, d=0.68)$ and (slightly) possessing less shortterm mate value $(t[280]=1.74, p<.09, d=0.20)$ were more likely to have used Tinder in the last year compared to those who had not used it. H3b suggests these mate value effects should be strongest in women as opposed to men. Consistent with that, in women, the effects for general undesirability $(t[164]=6.01, p<.01, d=0.94)$ short-term mate value $(t[164]=1.69, p<.10, d=0.26)$ did not change. In men, there was a slight effect for general undesirability $(t[112]=1.79, p<.08, d=0.34)$.

\section{DISCUSSION}

Today, millions of people around the world use dating applications like Tinder (e.g., Duguay, 2016). Researchers have invested time trying to understand who uses Tinder and why (Gatter \& Hodkinson, 2016; Sevi, 2018; Sevi et al., 2018; Sumter et al., 2017; Timmermans \& De Caluwé, 2017a, 2017b). Researchers, however, have focused on a limited range of personality traits that are directly tied to sex like sociosexuality and sexual disgust (e.g., Botnen et al., 2018; Sevi, 2019) and others that are perhaps too general to be useful for theory-testing like the Big Five traits (e.g., Timmermans \& De Caluwé, 2017a). In two brief studies, we examined whether those who use Tinder (as compared to those who do not) were characterized by individual differences in the Dark Triad traits, attachment, and mate value.

Taking the casual sex motives of Tinder use (Sevi, 2019) and the potential for cyberbullying (March et al., 2017), as givens, we predicted that traits that lead people to engage in casual sex and be aggressive should be related to Tinder use. The Dark Triad traits of psychopathy, narcissism, and (slightly) Machiavellianism were higher in Tinder users than non-users. These traits have been reliably linked to casual sex attitudes and behaviors (Jonason et al., 2009; Jonason et al., 2011) and online aggressiveness (Duncan \& March, 2019). If our assumption that Tinder usage is partially related to casual sex is true, traits that enable casual sex behavior like the Dark Triad should be higher in users. Indeed, if the traits facilitate short-term mating in men more than women (Jonason et al., 2009), we should have found that only male Tinder users were higher in the Dark Triad trait than non-users. Our evidence was consistent with these predictions and prior work (Sevi, 2019; Timmermans et al., 2018).

We also found that those who are anxiously attached were likely to be Tinder users more than non-users but found no difference across usage for those with avoidant attachment. Those with anxious attachment may need interpersonal contact because of their dysfunctional attachment history (Batholomew \& Horowitz, 1991; Schachner \& Shaver, 2004).

\footnotetext{
8 Relationship status and application use did not interact to predict the personality traits $\left(p_{\mathrm{s}}=.38\right.$ to .80$)$, but generally we avoided multivariate tests because of the sample sizes. More details available upon request.
} 
Those with an anxious attachment pattern may have a "hole in their heart" that they attempt to fill through the use of casual sex and Tinder use. This effect was in women but not in men. It may be that women who are anxiously attached try to fill in this hole by connecting with others (Kruger \& Fisher, 2008) whereas men who are anxiously attached fill in the hole with antisocial behaviors like drug use. For women, social connection is more of a fundamental need than it is for men given the evolutionary pressures that social connection solves (Jonason \& Zeigler-Hill, 2018). If ancestral women benefited more from group-living than men did (e.g., protection from predators, protection from men), the anxiety in their attachment mechanisms may be a warning signal; a warning signal that, today, encourages them to seek out others on Tinder for attachment needs.

Last, we also asserted that Tinder might be a compensatory mating strategy. We expect that people would prefer meeting their partners in their day-to-day life and in person, but when this is not possible, they may use Tinder to find the relationships and sex they want. The evolutionary history of human mating was surely characterized by face-to-face meetings, and there might be biases in mate selection mechanisms that need certain inputs (e.g., voice, attractiveness); inputs that Tinder dating fails to provide well or at all. In addition, Tinder dating may also come with new costs (e.g., ghosting) that people are ill-equipped to deal with in their dating lives. If we are correct, we would expect that it is those who feel they have less success in their dating lives be the ones who are on Tinder compared to those who are not. Indeed, we found that those who used Tinder in the last year felt they were undesirable as a mate and even low in short-term mate value. Those who feel they have had limited success on the mating market may have to engage in compensatory mating tactics (Jonason, Betes, \& Li, in press), of which, joining Tinder might be one. Interestingly, we found this effect was female-specific. Women who feel they are desirable as a mate, may not feel the need to join Tinder. They are likely to have (or expect to have) sufficient interest from people in their offline lives. However, women who feel they are less desirable, may have experienced sufficient amounts of relationship failures that Tinder (and other dating applications) is a viable compensatory mating tactic for them to adopt. Men, in contrast, may use Tinder regardless of their mate value to optimize mating opportunities in an implicit bet-hedging strategy as would be expected by people high in the Dark Triad traits.

\section{LIMITATIONS AND CONCLUSIONS}

Despite a unique set of variables and predictions derived from evolutionary psychology to understand who uses dating applications, our studies are characterized by several limitations. First, our samples are W.E.I.R.D. (i.e., Western, educated, industrialized, rich, and democratic; Henrich, Heine, \& Norenzayan, 2010). Second, we somewhat ignored other dating applications individuals could use and if they were using more than one, both of which might be further revealing. Third, our samples were imbalanced as to user to non-user comparisons which has implications for the power to detect relationships. This was especially problematic for sex-specific tests, and yet, we found effects consistent with predictions. That is, even with technically underpowered tests, our findings largely align with our predictions. Nevertheless, this makes our results especially tentative. Fourth, our results are mute on the issue of sexual orientation (Clemens et al., 2015), but we suspect similar effects as we found here and our question regarding dating application use could be construed to include homosexual-specific applications like Grindr. Fifth, we did not control for shared variance in the traits which, along with the multiple tests, may have inflated the Type 1 error, but given the potential for limited power, we aired towards Type 1 error over Type 2 error; using planned comparisons over omnibus tests. Sixth, given the array of potential reasons people may use dating application for, our questions asking about 
use compared to non-use may be a rough instrument only (Timmermans et al., 2018). Likert-style questions may reveal more nuance (e.g., willingness to use Tinder) and will have more power than our behavioroid measure. Seventh, it is possible that the effects we found may be further mediated by the motivations that people may have for using the applications. It is possible that those high on the Dark Triad traits are expressly using these applications for sex whereas those with anxious attachment may be using the applications for relationships; both of which seem like logical predictions given what is known about each trait. And if these two parties meet, there is likely potential relationship problems in this couples' future. Eighth, we did not include (e.g., relationship duration) or control for potential demographics (i.e., participant's age) in our analyses. Relationship duration was not viewed as an important variable to test our hypotheses. Age appears to have an irregular relationship with Tinder use in our studies as noted in footnotes above. Controlling for age and sex (for example) would (1) further diminish the power of the tests, (2) increase the exploratory nature of this study, and (3) treats age and sex as nuisance variables. Especially for participant's sex, we think it an error to treat participant's sex as a nuisance variable. Ninth, our data is cross-sectional. Future, experimental/longitudinal work on dating applications is warranted because we are sure they are here to stay and may irrevocably change how men and women connect. Despite these limitations, we have detailed new information about who uses dating applications.

While considerable work exists on who uses dating applications like Tinder (Sevi, 2019; Timmermans et al., 2018), researchers have yet to fully explore the role of the Dark Triad traits (e.g., moderation by participant's sex) and have yet to examine attachment and mate value. Although exploratory, our results suggest that male Tinder users might be especially psychopathic and narcissistic and female Tinder users might be especially anxious in their attachment and have had difficulties finding relationship partners. Together this creates a potentially dangerous combination of people using Tinder; men who may exploit others and women who may be prone to exploitation. It will be essential to better identify who uses these applications as a means of protecting others from exploitation but also to better enable people's mating interests.

\section{A C K N O W LED GEMENTS}

Authors' note: The first author was partially funded by the Polish National Agency for Academic Exchange. The paper was presented under different titles by the second author at the Australian Conference for Personality and Individual Differences (2017) and the European Conference on Personality (2018). We thank Evita March for reviewing an earlier version of our paper.

\section{REFERENCES}

Ainsworth, M. D. S., Blehar, M. C., Waters, E., \& Wall, S. (1978). Patterns of attachment: Assessed in the strange situation and at home. Hillsdale, NJ: Erlbaum.

Aretz, W., Demuth, I., Schmidt, K., \& Vierlein, J. (2010). Partner search in the digital age. Psychological characteristics of online-dating-service-users and its contribution to the explanation of different patterns of utilization. Journal of Business and Media Psychology, 1, 8-16.

Batholomew, K., \& Horowitz, L. M. (1991). Attachment styles among young adults: A test of a four-category model. Journal of Personality and Social Psychology, 61, 226-244.

Botnen, E. 0., Bendixen, M., Grøntvedt, T. V., \& Kennair, L. E. 0. (2018). Individual differences in sociosexuality predicts picture-based mobile dating app use. Personality and Individual Differences, 131, 67-73. 
Brennan, K. A., \& Shaver, P. R. (1995). Dimensions of adult attachment, affect regulation, and romantic relationship functioning. Personality and Social Psychological Bulletin, 27(3), 267-283.

Buss, D. M., \& Schmitt, D. P. (1993). Sexual strategies theory: An evolutionary perspective on human mating. Psychological Review, 100(2), $204-232$.

Carpenter, C. J., \& McEwan, B. (2016). The players of micro-dating: Individual and gender differences in goal orientations toward micro-dating apps. First Monday, 21(5). https://doi.org/10.5210/fm.v21i5.6187

Cassidy, J., \& Shaver, P. R. (1999). Handbook of attachment. New York, NY: Guilford.

Clemens, C., Atkins, D., \& Krishnan, A. (2015). The influence of biological and personality traits on gratifications obtained through online dating websites. Computers in Human Behavior, 49, 120-129.

Daneback, K., Månsson, S. A., \& Ross, M. (2007). Using the internet to find offline sex partners. CyberPsychology \& Behavior, 10(1), 100-107.

Duggan, M., \& Smith, A. (2014, January). Social media update 2013. Retrieved March 12, 2019, from https://www.pewresearch.org/internet/2013/12/30/social-media-update-2013/

Duguay, S. (2016). Dressing up Tinderella: Interrogating authenticity claims on the mobile dating app Tinder. Information, Communication \& Society, 20 (3), 1-17.

Duncan, Z., \& March, E. (2019). Using Tinder ${ }^{\circledast}$ to start a fire: Predicting antisocial use of Tinder ${ }^{\circledast}$ with gender and the Dark Tetrad. Personality and Individual Differences, 145, 9-14.

Edlund, J. E., \& Sagarin, B. J. (2010). Mate value and mate preferences: An investigation into decisions made with and without constraints. Personality and Individual Differences, 49(8), 835-839.

Fisher, M., Cox, A., Bennett, S., \& Gavric, D. (2008). Components of self-perceived mate value. Journal of Social, Evolutionary, and Cultural Psychology, 2(4), $156-168$.

Fraley, R. C., Waller, N. G., \& Brennan, K. A. (2000). An item-response theory analysis of self-report measures of adult attachment. Journal of Personality and Social Psychology, 78(2), 350-365.

Gatter, K., \& Hodkinson, K. (2016). On the differences between Tinder ${ }^{\mathrm{Tm}}$ and online dating agencies: Questioning a myth. An exploratory study. Cogent Psychology, $3(1), 1-12$.

Hazan, C., \& Shaver, P. R. (1987). Romantic love conceptualized as an attachment process. Journal of Personality and Social Psychology, 52(3), 511-524.

Henrich, J., Heine, S. J., \& Norenzayan, A. (2010). The weirdest people in the world? Behavioral and Brain Sciences, 33(2-3), 61-83.

Jonason, P. K., Betes, S. L., \& Li, N. P. (in press). Solving mate shortages: Lowering standards, traveling farther, and abstaining. Evolutionary Behavioral Sciences.

Jonason, P. K., Foster, J. D., McCain, J., \& Campbell, W. K. (2015). Where birds flock to get together: The who, what, where, and why of mate searching. Personality and Individual Differences, 80, 76-84.

Jonason, P. K., Foster, J. D., Oshio, A., Sitnikova, M., Birkas, B., \& Gouveia, V. (2017). Self-construals and the Dark Triad traits in six countries. Personality and Individual Differences, 113, 120-124.

Jonason, P. K., Garcia, J., Webster, G. D., Li, N. P., \& Fisher, H. (2015). Relationship dealbreakers: Traits people avoid in potential mates?. Personality and Social Psychological Bulletin, 41(12), 1697-1711.

Jonason, P. K., Li, N. P., Webster, G. W., Schmitt, D. P. (2009). The Dark Triad: Facilitating short-term mating in men. European Journal of Personality, 23(1), 5-18.

Jonason, P. K., Lyons, M., \& Bethell, E. (2014). The making of Darth Vader: Parent-child care and the Dark Triad. Personality and Individual Differences, 67, 30-34.

Jonason, P. K., Marsh, K., Dib, 0., Plush, D., Doszpot, M., Fung, E., Crimmins, K., Drapski, M., \& Di Pietro, K. (2019). Is smart sexy?: Examining the role of relative intelligence in mate preferences. Personality and Individual Differences, 139, 53-59.

Jonason, P. K., Valentine, K. A., Li, N. P., \& Harbeson, C. L. (2011). Mate-selection and the Dark Triad: Facilitating a short-term mating strategy and creating a volatile environment. Personality and Individual Differences, 51(6), 759-763.

Jonason, P. K., \& Zeigler-Hill, V. (2018). The fundamental social motives that characterize dark personality traits. Personality and Individual Differences, $132,98-107$. Jones, D. N., \& Paulhus, D. L. (2014). Introducing the Short Dark Triad (SD3): A brief measure of dark personality traits. Assessment, 21(1), 28-41.

Kim, M., Kwon, K., \& Lee, M. (2009). Psychological characteristics of Internet dating service users: The effect of self-esteem, involvement, and sociability on the use of Internet dating services. Cyberpsychology \& Behavior, 12(4), 445-449.

Koehn, M. A., Okan, C., \& Jonason, P. K. (2019). A primer on the Dark Triad traits. Australian Journal of Psychology, 71(1), 7-15.

Kraut, R., Kiesler, S., Boneva, B., Cummings, J., Helgeson, V., \& Crawford, A. (2002). Internet paradox revisited. Journal of Social Issues, 58(1), 49-74.

Kraut, R., Patterson, M., Lundmark, V., Kiesler, S., Mukophadhyay, T., \& Scherlis, W. (1998). Internet paradox: A social technology that reduces social involvement and psychological well-being? American Psychologist, 53(9), 1017-1031.

Kruger, D. J., \& Fisher, M. L. (2008). Women's life history attributes are associated with preferences in mating relationships. Evolutionary Psychology, 6(2), 289-302.

Li, N. P. (2017). A multidimensional measure of self-reported mate-value [Unpublished manuscript]. Singapore Management University.

March, E., Grieve, R., Marrington, J., \& Jonason, P. K. (2017). Trolling on Tinder (and other dating apps): Examining the role of the Dark Tetrad and impulsivity. Personality and Individual Differences, 110, 139-143.

Mikulincer, M., \& Shaver, P. R. (2003). The attachment behavioral activation system in adulthood: Activation, psychodynamics, and interpersonal processes. In M. P. Zanna (Ed.), Advances in experimental social psychology (Vol. 35). San Diego, CA: Academic Press.

Regan, P.C. (1998). What if you can't get what you want?: Willingness to compromise ideal mate selection standards as a function of sex, mate value, and relationship context. Personality and Social Psychology Bulletin, 24(12), 1294-1303.

Richard, F. D., Bond, C. F., Jr., \& Stokes-Zoota, J. J. (2003). One hundred years of social psychology quantitatively described. Review of General Psychology, 7(4), $331-363$.

Sales, N. J. (2015, September). Tinder and the dawn of the "dating apocalypse". Vanity Fair. Retrieved March 12, 2019, from http://www.vanityfair.com/culture/2015/08/tinder-hook-up-culture-end-of-dating

Schachner, D. A., \& Shaver, P. R. (2004). Attachment dimensions and sexual motives. Personal Relationships, 11(2), 179-195.

Schönbrodt, F. D., \& Perugini, M. (2013). At what sample size do correlations stabilize? Journal of Research in Personality, 47(5), 609-612.

Schmitt, D. P., \& Jonason, P. K. (2015). Attachment and sexual permissiveness: Exploring differential associations across genders, cultures, and facets of short-term mating. Journal of Cross Cultural Psychology, 46, 119-133. 
Sevi, B. (2018). Tinder users are risk takers and have low sexual disgust sensitivity. Evolutionary Psychological Science, 5, 104-108.

Sevi, B. (2019). The dark side of Tinder: The Dark Triad of personality as correlates of Tinder use. Journal of Individual Differences. Advance online publication.

Sevi, B., Aral, T., \& Eskenazi, T. (2018). Exploring the hook-up app: Low sexual disgust and high sociosexuality predict motivation to use Tinder for casual sex. Personality and Individual Differences, 133, 17-20.

Shaver, P. R., \& Brennan, K. A. (1992). Attachment styles and the "Big Five" personality traits: Their connections with each other and with romantic relationship outcomes. Personality and Social Psychology Bulletin, 18, 536-545.

Sprecher, S. (2013). Attachment style and sexual permissiveness: The moderating role of gender. Personality and Individual Differences, 55, 428-432.

Sumter, S. R., Vandenbosch, L., \& Ligtenberg, L. (2017). Love me Tinder: Untangling emerging adults' motivations for using the dating application Tinder. Telematics and Informatics, 34(1), 67-78.

Timmermans, E., \& De Caluwé, E. (2017a). To Tinder or not to Tinder, that's the question: An individual differences perspective to Tinder use and motives. Personality and Individual Differences, $110,74-79$

Timmermans, E., \& De Caluwé, E. (2017b). Development and validation of the Tinder Motives Scale (TMS). Computers in Human Behavior, 70, $341-350$.

Timmermans, E., De Caluwé, E., \& Alexopoulos, C. (2018). Why are you cheating on Tinder?: Exploring users' motives and (dark) personality traits. Computers in Human Behavior, 89, 129-139.

Valkenburg, P., \& Peter, J. (2007). Who visits online dating sites? Exploring some characteristics of online daters. Cyberpsychology \& Behavior, 10(6), 849-852.

Whitty, M. T., \& Buchanan, T. (2009). Looking for love in so many places: Characteristics of online daters and speed daters. Interpersona: An International Journal on Personal Relationships, 3, 63-86. 